\title{
Selección e identificación de una nueva bacteria productora de pectinasa a partir de fuentes geotermales
}

Selection and identification of a new pectinase-producing bacterium from geothermal sourcesconomic valuation of the Vilacota Maure Regional Conservation Area: Priority ecosystem services to the extreme south of Peru

\author{
${ }^{1, \mathrm{a}}$ Israel Salazar \\ ${ }^{1, b}$ Heber Ramírez \\ ${ }^{1, \mathrm{c}}$ Ariadna Zúñiga \\ ${ }^{1, \mathrm{~d}}$ Mirella Yllanes
}

\author{
${ }^{1, e}$ Ana Naquiche \\ 1,f Daladier Castillo \\ ${ }^{1, g}$ Roberto Castellanos
}

\section{COMUNICACIÓN CORTA \\ ${ }^{1}$ Universidad Nacional Jorge Basadre Grohmann. Tacna, Perú.}

\begin{abstract}
${ }^{\mathrm{a} O R C I D: 0000-0003-3255-5038}$
'ORCID: 0000-0001-9122-7929

'ORCID: 0000-0001-6304-0745

dORCID: 0000-0001-8561-4586

'ORCID: 0000-0002-7455-3076

fORCID: 0000-0003-0133-5921

${ }^{\mathrm{g}}$ ORCID: 0000-0002-9021-412X
\end{abstract}

Palabras clave: Bacterias termofílicas, géiseres térmicos, pectinasas

Keywords: Thermophilic bacteria, thermal geysers, pectinases.

\section{Información adicional}

Presentado: 10/10/2020

Aprobado: 20/12/2020

\section{RESUMEN}

Los microorganismos son una fuente potencial de enzimas. Las bacterias termófilas producen enzimas termoestables, como las pectinasas, que permiten obtener una serie de productos que hidrolizan pectinas, heteropolisacáridos, componentes principales de la capa media de la pared celular de la piel de los cítricos (naranjas, limones y mandarinas), manzanas, melocotones y otros vegetales. El cultivo bacteriano productor de pectinasas se seleccionó de bacterias aisladas de géiseres de aguas termales. Las muestras se sembraron en medio líquido y sólido, se incubaron a $60{ }^{\circ} \mathrm{C}$ durante 24 a 48 horas respectivamente, observándose halos de hidrólisis como indicativos de producción de pectinasa. Las bacterias que formaron los halos se sembraron en medio de producción de pectinasas, evaluando su actividad enzimática y producción de proteínas. Se aislaron veinte cultivos bacterianos gram positivos, de los cuales 12 fueron productores de pectinasas, siendo el cultivo LBE-P4 el de mayor actividad enzimática con $0.154 \mathrm{U} / \mathrm{ml}$ y $0.069 \mathrm{mg} / \mathrm{ml}$ de proteínas totales, que fue identificado molecularmente como Geobacillus kaustophilus LBE-P4.

\section{ABSTRACT}

Microorganisms are a potential source of enzymes. Thermophilic bacteria produce thermostable enzymes, such as pectinases, which make it possible to obtain a series of products that hydrolyze pectins, heteropolysaccharides, the main components of the middle layer of the cell wall of citrus fruit peels (oranges, lemons and tangerines), apples, peaches and other vegetables. The pectinase producing bacterial culture was selected from bacteria isolated from thermal water geysers. The samples were seeded in liquid and solid medium, incubated at $60{ }^{\circ} \mathrm{C}$ for 24 to 48 hours respectively, observing hydrolysis halos as indicative of pectinase production. The bacteria that formed the halos were seeded in pectinase production medium, evaluating their enzymatic activity and protein production. Twenty gram positive bacterial cultures were isolated, of which twelve were pectinase producers, being the LBE-P4 culture the one with the highest enzymatic activity with $0.154 \mathrm{U} / \mathrm{ml}$ and $0.069 \mathrm{mg} / \mathrm{ml}$ of total proteins, being possible its optimization, which was molecularly identified as Geobacillus kaustophilus LBE-P4. 


\section{INTRODUCCIÓN}

Los manantiales geotérmicos poseen agua con temperaturas mayores a $45{ }^{\circ} \mathrm{C}$, existiendo una gran diversidad microbiana. Estos microorganismos constituyen fuentes potenciales productoras de enzimas de interés industrial. La pectinasa es una de estas enzimas que se utiliza en procesos industriales y es obtenida de bacterias, hongos, levaduras, plantas superiores (Jhon et al., 2020). Las que se obtienen a partir de microorganismos termófilos pueden contribuir a la reducción de tiempo y esfuerzo invertido en los procesos industriales en el que son aplicados. Además, se reducen los riesgos de contaminación.

Entre los microorganismos productores de pectinasas están Geotrichum klebahnii (levadura), Bacillus spp, Aspergillus flavus, Aspergillus pulverulentus (Abd El-Rahim et al., 2020), Bacillus subtilis, Paenibacillus sp., Thermoanaerobacter italicus, Thermotoga maritima, Enterobacter agglomerans, Bacillus lincheniformis, Cándida krussei, Candida sorboxilosa, Candida insectorum, Aureobasidium pullulans var. pullulans, Aspergillus niger, Aspergillus sp., Penicillium sp., Mucor sp., Microsporum sp. (Li et al., 2020).

El sustrato de la pectinasa es la pectina que se encuentra en las paredes celulares de las células vegetales. Esto ha hecho que la industria para la obtención de una serie de productos (como los alimentos) utilice la pectinasa en la obtención del vino y de los jugos, mejorando la licuefacción, el rendimiento del jugo, la clarificación, la capacidad de filtración y el aumento de la liberación de compuestos de color y sabor atrapados en el tejido vegetal (Jhon et al., 2020).

La importancia de las pectinasas ha hecho que su comercialización aumente aceleradamente en el mercado (Roy et al., 2018). Su crecimiento anual promedio de 27.6 millones de dólares en el 2013 aumentó a 30 millones de dólares en el 2016, estimándose que aumentará hasta 35.5 millones de dólares para el 2021 (Jhon et al., 2020).

Las fuentes bacterianas para la producción de pectinasas tienen considerables ventajas: altas tasas de crecimiento en tiempos cortos de fermentación, capacidad de secretar proteínas extracelulares y adaptación a las condiciones ambientales y nutricionales cambiantes. La producción de estas moléculas biológicamente activas, proporcionan un alto potencial para aplicaciones biotecnológicas (Roy et al., 2018). Su descubrimiento y estudio es importante para aplicaciones comerciales en la industria (Kubra et al, 2018).

La determinación de la capacidad enzimática de un tipo de enzima es de vital importancia para conocer el tipo de sustrato que va a degradar. Esta actividad enzimática se mide en términos de unidad de actividad enzimática(U), actividad catalítica responsable de la transformación de un micromol de sustrato por minuto en condiciones óptimas de la enzima (Chaiyasut et al., 2013).

El objetivo del presente trabajo fue seleccionar el mejor cultivo bacteriano pectinolítico a partir de bacterias aisladas de géiseres en base a la mayor actividad enzimática de pectinasa, para su posterior identificación molecular.

\section{MATERIAL Y MÉTODOS}

\section{Aislamiento y selección de bacterias}

Se recolectó $250 \mathrm{~g}$ de sedimento y $1 \mathrm{~L}$ de agua de cada géiser de un total de 11 géiseres ubicados en Calientes, Candarave (Tacna, Perú). En laboratorio, se procedió a realizar un enriquecimiento. Para cada muestra de géiser, se preparó en matraces $90 \mathrm{ml}$ de caldo Luria Bertani (LB). Se utilizó como diluyente el agua de géiser filtrada en una membrana de $0.2 \mu \mathrm{m}$, y se agregó $10 \mathrm{~g}$ del sedimento de géiser. La incubación se hizo a $60^{\circ} \mathrm{C}$ durante 48 horas. 
Para obtener colonias aisladas, las muestras de los cultivos enriquecidos fueron diluidas en Solución Salina Fisiológica (S.S.F.) hasta $10^{-5}$, sembradas en placas Petri conteniendo agar LB (preparado con agua de los géiseres filtrada) por incorporación e incubadas a $60{ }^{\circ} \mathrm{C}$ hasta 48 horas. Las colonias obtenidas fueron repicadas en el mismo medio agar LB para obtenerlas puras, a las cuales se les hizo coloración de Gram.

\section{Selección cualitativa de la enzima pectinasa}

Para la selección de los cultivos bacterianos pectinolíticos se usó el método de Ahlawat et al. (2007). Los cultivos aislados fueron sembrados por puntura en el medio de cultivo sólido conteniendo: peptona $5 \mathrm{~g} / \mathrm{L}$, extracto de carne $3 \mathrm{~g} / \mathrm{L}$, agar $20 \mathrm{~g} / \mathrm{L}$, y pectina $5 \mathrm{~g} / \mathrm{L}$, ajustado a $\mathrm{pH} 7.0$, e incubados a $60^{\circ} \mathrm{C}$ por 24 - 48 horas. Se seleccionaron como productoras de pectinasas a las colonias que mostraron ante el agregado de solución de lugol $30 \%(\mathrm{v} / \mathrm{v})$ zonas de hidrólisis.

\section{Evaluación de la producción de pectinasa}

Los cultivos pectinolíticos fueron sembrados en el medio líquido de producción de pectinasas (extracto de levadura $1 \mathrm{~g} / \mathrm{L}$, pectina $2.5 \mathrm{~g} / \mathrm{L}, \mathrm{MgSO}_{4} 0.5 \mathrm{~g} / \mathrm{L}, \mathrm{CaCl}_{2} 0.5 \mathrm{~g} / \mathrm{L}$ ), según Kashyap et al. (2000). Luego, fueron incubados a $60{ }^{\circ} \mathrm{C}$ con agitación orbital de $150 \mathrm{rpm}$, durante 48 horas, y centrifugados a $10000 \mathrm{rpm}$ por 10 minutos para la obtención de las pectinasas en el sobrenadante, el cual sirvió para determinar la actividad enzimática y la producción de proteínas de las pectinasas.

\section{Cuantificación de proteínas totales}

La determinación de proteínas totales del extracto crudo se realizó por el método de Bradford a una longitud de onda de $595 \mathrm{~nm}$ (Bradford, 1973).

\section{Determinación de Actividad Pectinasa}

La medición de la actividad enzimática de las pectinasas fue realizada utilizando el método de Miller (1959) modificada por Chaiyasut et al. (2013). Entonces, se utilizó pectina de manzana como sustrato al $0.5 \%$, la cual fue disuelta en buffer fosfato de sodio $0.05 \mathrm{M}(\mathrm{pH}$ 7.0). Las lecturas de absorbancias se hicieron en el lector de microplaca EPOCH 2 (Biotek Instrument Inc., USA) a $540 \mathrm{~nm}$. El cálculo de la actividad enzimática de pectinasas se hizo según la ecuación:

\section{Actividad Enzimática $(\mathrm{U} / \mathrm{ml})=\underline{\text { Acido galacturónico }(\mu \mathrm{mol} / \mathrm{ml}) \times \text { Volumen Total }(\mathrm{ml})}$ \\ Extracto enzimático (ml) x Tiempo de reacción (min)}

La actividad enzimática se expresó en unidades de enzima por mililitro de sustrato. Una unidad enzimática se definió como la cantidad de enzima que libera un micromol de ácido galacturónico por minuto (U/ml).

\section{Identificación molecular de la cepa seleccionada}

El cultivo con mayor actividad pectinolítica fue identificado molecularmente mediante el análisis de la secuencia del gen ADNr 16S. La extracción del ADN genómico se realizó mediante el kit Bacterial Genomic DNA isolation (Biotek Corp., Canada, Cat. 00098). En la amplificación del ADNr 16S se utilizaron los primers 27F (5'AGAGTTTGATCCTGGCTCAG-3') y 1492R (5'GGTTACCTTGTTACGACTT-3') y el Kit 2X PCR Taq Master Mix (abm, Canada, cat.), de acuerdo a las especificaciones del fabricante. Se utilizó el termociclador ProFlexTM (Applied biosistems-Thermo Fisher Scientific, USA) con el siguiente programa: ciclo inicial de $95^{\circ} \mathrm{C}$ de 5 min, seguido de 35 ciclos a $95^{\circ} \mathrm{C}$ por $40 \mathrm{~s}, 55^{\circ} \mathrm{C}$ por $40 \mathrm{~s}, 72^{\circ} \mathrm{C}$ por $1 \mathrm{~h} 30 \mathrm{~min}$, y una temperatura de extensión final de $10 \mathrm{~min}$ a $72^{\circ} \mathrm{C}$. El producto amplificado fue observado mediante corrida electroforética en gel de agarosa al $1 \%$ y luego enviado a la empresa Macrogen Inc., (Korea) para la secuenciación y análisis.

Las secuencias de ambas cadenas se agruparon, alinearon y corrigieron de forma paralela utilizando el software MEGAX. Se realizó una búsqueda de identidad comparativa de la secuencia obtenida utilizando la herramienta BLAST (Búsqueda de alineación local básica) de la base de datos del Centro Nacional de Información en Biotecnología (NCBI) y de EzBioCloud. La tasa de similitud se verificó y recibió el número de accesión GenBank de la misma manera que Tamura et al. (2007). 


\section{RESULTADOS}

El lugar de muestreo se ubica a los $4100 \mathrm{~m} \mathrm{s.} \mathrm{n.} \mathrm{m.,} \mathrm{a} 20 \mathrm{Km}$ del pueblo de Candarave, donde se ubican los volcanes Yucamani Mayor y Yucamani Menor, actualmente sin actividad. Como resultado de su inactividad, a su alrededor se han formado un aproximado de 85 géiseres de donde brotan aguas calientes, muchas de ellas cristalinas, compuestas de una gran cantidad de minerales, ligeros y pesados (Figura 1).
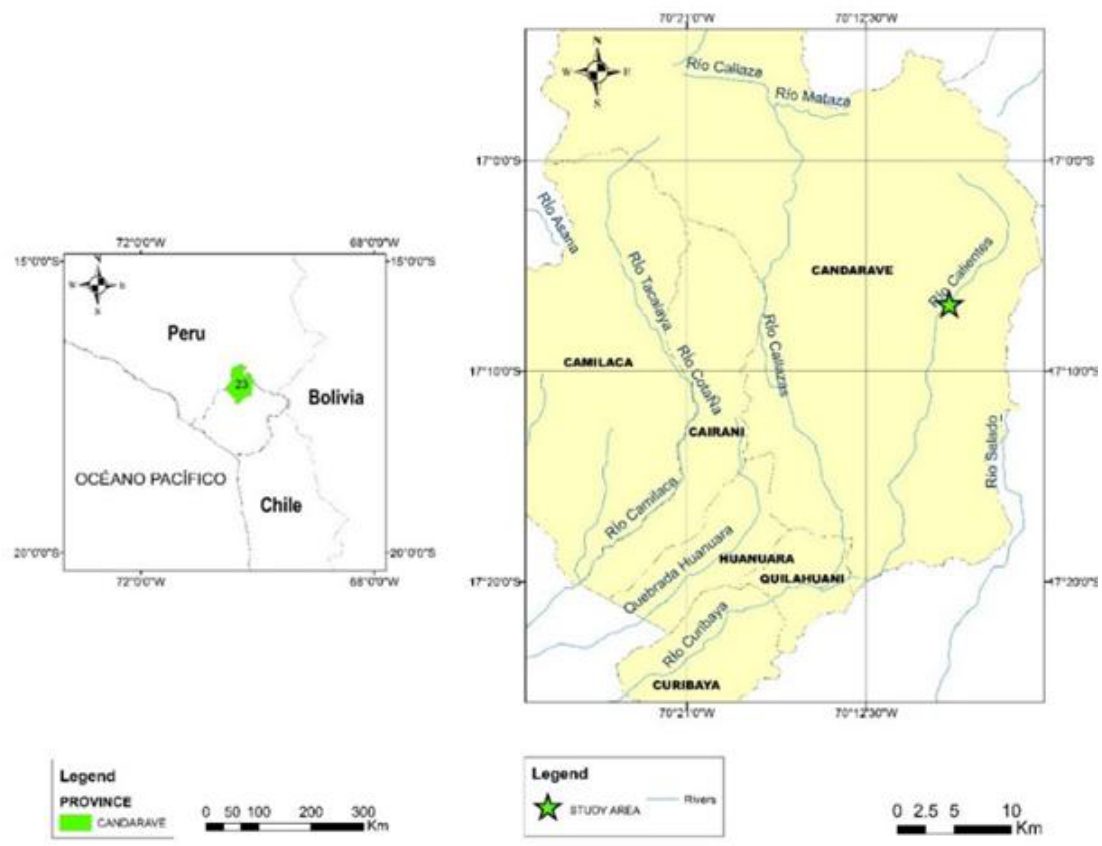

Figura 1. Zona de muestreo de los géiseres de calientes, Candarave (Tacna, Perú), ubicada a 4100 ms.n.m.

En el presente estudio, de todas las muestras procesadas (20 cultivos), se obtuvieron 12 cultivos positivos, dado que se tratan de bacterias termófilas ambientales incultivables. Se tuvo que realizar screening tentativos para determinar la cepa que codifica el gen de la pectinasa. Esto se logró cualitativamente mediante la formación de halos en placas Petri conteniendo los medios de cultivo. Debe indicarse que todos los cultivos microbianos eran gram positivos.

Solamente 12 cultivos fueron productores de pectinasas en base a la formación de halos de hidrólisis, de los cuales se seleccionó a la cepa LBE-P4 por presentar mayor zona de hidrólisis (Figura 2).

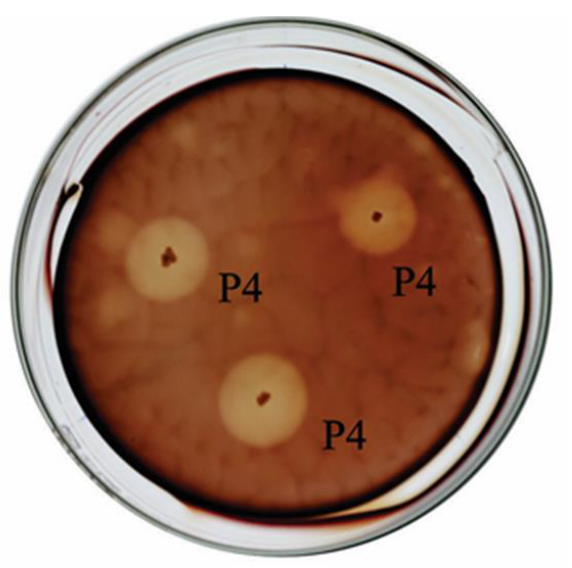

Figura 2. Halos de hidrólisis por pectinasas producidas por el cultivo LBE-PA 
El cultivo con mayor actividad enzimática fue el cultivo P4 con un valor de $0.154 \mathrm{U} / \mathrm{ml}$ de actividad enzimática y $0.069 \mathrm{mg} / \mathrm{ml}$ de proteínas totales (Tabla 1 ).

Tabla 1

Actividad enzimática y proteínas totales de los 12 cultivos productores de pectinasas

\begin{tabular}{ccc}
\hline Cepa & $\begin{array}{c}\text { Actividad } \\
\text { enzimática } \\
\text { (U/ml) }\end{array}$ & $\begin{array}{c}\text { Proteínas } \\
\text { totales (mg/ml) }\end{array}$ \\
\hline CB-13 & 0.147 & 0.057 \\
CB-16 & 0.139 & 0.031 \\
CB-19 & 0.129 & 0.028 \\
CB-28 & 0.134 & 0.058 \\
FT-3 & 0.094 & 0.045 \\
FT-4 & 0.108 & 0.039 \\
FT-8 & 0.131 & 0.040 \\
TM-1 & 0.133 & 0.045 \\
TM-10 & 0.080 & 0.052 \\
TM-13 & 0.130 & 0.090 \\
GT-5 & 0.079 & 0.041 \\
P4 & 0.154 & 0.069 \\
\hline
\end{tabular}

El cultivo P4 se identificó molecularmente como Geobacillus kautiphilus LBE-P4, según el análisis de secuenciación del gen ARNr 16S. Esta secuencia (Accesión GenBank: MN830248) contuvo 1371 nucleótidos (nt) y presentó similitud a Geobacillus kaustophilus (Accesión: BBJV01000091) y Geobacillus thermoleovorans (Accesión: CP014335), ambos con una tasa del $99.93 \%$ en la base de datos EzBioCloud. Asimismo, tuvo un $99.85 \%$ de identidad con Geobacillus kaustophilus (Accesión: NR_115285.2) en la base de datos GenBank (Figura 3).

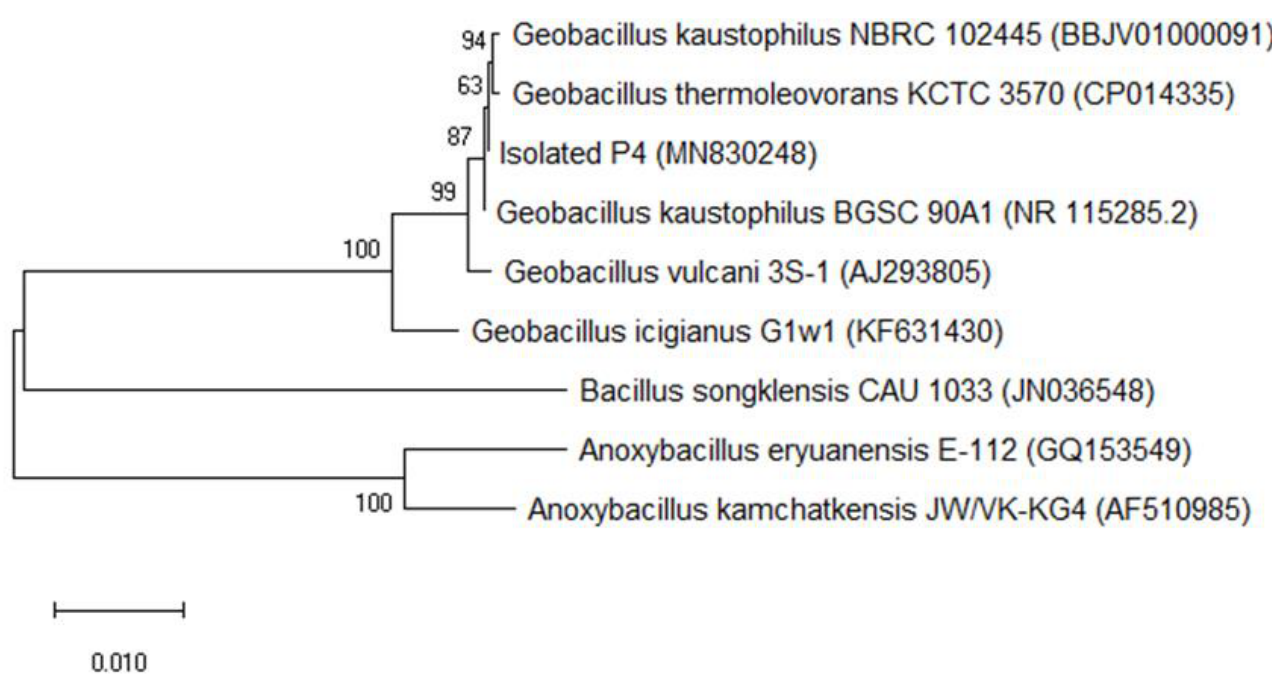

Figura 3. Árbol filogenético de la secuencia de datos del gen 16S rRNA del cultivo P4 construido por el método Neighbor-Joining.

Nota: Las distancias evolutivas se calcularon utilizando el método de máxima verosimilitud compuesta. Los análisis evolutivos se realizaron en MEGA X. Los números de acceso GenBank se muestran entre paréntesis. Los taxones que están asociados se muestran en las ramas con similitud, identificándose a la cepa $\mathrm{P} 4$ como Geobacillus kaustophilus LBE-P4. 


\section{DISCUSIÓN}

Los lugares de condiciones extremas son frecuentemente utilizados como fuentes de microorganismos para obtener metabolitos utilizados en diferentes procesos industriales. Los géiseres de Calientes (Candarave, Tacna, Perú), con temperaturas que oscilan entre 50 y $90^{\circ} \mathrm{C}$, constituyen uno de estos lugares donde se han encontrado diversos microorganismos con variadas capacidades (Zapata \& Castellanos, 2014; Naquiche, 2014). Incluyen a los cultivos con capacidad de producción de pectinasas, siendo algunos esporulados; sin embargo en el presente trabajo, todos fueron bacilos y gram positivo. Entonces, estos géiseres son importantes como fuente natural de una diversidad microbiana para diferentes fines como la obtención de enzimas de interés industrial.

Las bacterias aisladas son diferentes a los de otros ambientes extremos por las características físicas y químicas que varían entre un lugar y otro. Por ello, se entiende el reporte de diferentes aislamientos, de bacterias productoras de pectinasas como el de Geobacillus a partir de fuentes termales y salinas en Turquía (Guven et al., 2018), de Bacillus de otras fuentes termales y de otras bacterias del desierto en Egipto (Salem, 2018). Los Bacillus son bacilos esporulados gram positivos (Jhon et al., 2020). Los cultivos aislados en este trabajo son bacilos gram positivos, la mayoría no esporulados.

La producción de pectinasas en los cultivos seleccionados ha sido posible por la presencia de la pectina, sustrato de la pectinasa que funciona como inductor. En la producción de pectinasas bacterianas se aplica inductores como la pectina de manzana (Amin et al., 2018) que ayudan a expresar los genes productores de pectinasas en las bacterias.

El valor de actividad enzimática de la pectinasa de Geobacillus kaustophilus LBE-P4, $0.154 \mathrm{U} / \mathrm{ml}$, es diferente al de otras pectinasas que obtuvieron 2.265 U/ml como el trabajo de Abd El-Rahim et al. (2020). La diferencia entre estos resultados se explica porque las pectinasas proceden de diferentes microorganismos. La actividad enzimática se ha dado a diferentes condiciones ambientales como la temperatura; además, el sustrato pectina empleado para la actividad enzimática ha sido de diferente origen.

El cultivo LBE-P4 tuvo una alta similitud de su secuencia genómica y de capacidades con la bacteria del género Geobacillus, reportada como termófila en estudios realizados sobre aislados bacterianos de fuentes termales con capacidad de producir hidrolasas (Zapata \& Castellanos, 2014; Naquiche, 2014).

El género Bacillus es un grupo diverso de bacterias no monofiléticas que se ha subdividido paulatinamente en los nuevos géneros Brevibacillus, Paenibacillus, Salibacillus y últimamente Geobacillus, basado en agrupaciones filogenéticas separadas procedentes de información de secuencias del gen ARNr 16S. Por lo tanto, el cultivo P4 identificado como Geobacillus kaustophilus LBE-P4. es el producto de una subdivisión del género Bacillus. Geobacillus junto a las bacterias termófilas Anoxybacillus, Bacillus, Brevibacillus, Thermus y Aeribacillus, reportadas en otras fuentes termales como las de Turquía (Yildirim et al., 2017).

La selección e identificación de la bacteria LBE-P4 a partir de fuente geotermal permitió obtener un microorganismo capaz de producir este tipo de enzima muy resistente a altas temperaturas el cual puede ser aplicado en la industria presentando condiciones muy favorables de resistencia, durabilidad y evitando su desnaturalización temprana.

\section{CONCLUSIÓN}

Se seleccionó como bacteria termófila productora de pectinasas al cultivo LBE-P4, identificado molecularmente como Geobacillus kaustophilus LBE-P4., con una actividad enzimática de 0.154 U/ml. Con la cual, se obtuvo una cepa productora de enzima de interés industrial con capacidad de aplicación en la industria local como la vinícola mejorando el sabor y procesamiento de los vinos a partir de una fuente natural geotermal de la región Tacna, dando realce a esta zona y pudiendo aprovecharse como fuente futura de diversos tipos de microorganismos con interés biotecnológico. 


\section{AGRADECIMIENTO}

Los autores desean agradecer la asistencia financiera brindada por los fondos de canon y sobrecanon minero al proyecto de investigación "Producción biotecnológica de enzimas industriales a partir de microorganismos termófilos de los géiseres de Calientes, Candarave-Tacna", con Resolución Rectoral 3714-2018-UN/JBG. Asimismo, a las oficinas de investigación y autoridades que brindaron su apoyo para el presente estudio en la Universidad Nacional Jorge Basadre Grohmann, Tacna, Perú.

\section{REFERENCIAS}

Abd El-Rahim, W., Moawad, H., Hashem, M., Gebreil, G., \& Zacaria, M. (2020). Highly efficient fungal pectinase and laccase producers among isolates from flax retting liquor. Biocatalysis and Agricultural Biotechnology 25.

Ahlawat, S., Battan, B., Sudh, S., Sharma, J., \& Pal, R. (2007). Production of Thermostable Pectinase and Xylanase for Their Potential Application in Bleaching of Kraft Pulp. Journal of Industrial Microbiology \& Biotechnology 34(12): 763-70. https://doi.org/10.1007/s10295-007-0251-3.

Amin, F., Nawaz, H., \& Bilal, M. (2018). Recent Advances in the Production Strategies of Microbial Pectinases-A Review. International Journal of Biological Macromolecules, 22, 1017-1026. https://doi.org/10.1016/j.ijbiomac.2018.09.048.

Chaiyasut, C., Jantavong, S., Kruatama, C., Peerajan, S., Sirilun, S., \& Shank, L. (2013). Factors Affecting Methanol Content of Fermented Plant Beverage Containing Morinda Citrifolia. African Journal of Biotechnology, 12 (27), 4356-63. https://doi.org/10.5897/AJB10.1377.

Jhon, J., Surendranathan, K., Smith, M., Rahman, P., \& Velayudhaperumal, P. (2020). Advances in upstream and downstream strategies of pectinase bioprocessing: A review. International Journal of Biological Macromolecules, 162, 1086-1099.

Kashyap, D., Chandra, S., Kaul, A., \& Tewari. R. (2000). Production, Purification and Characterization of Pectinase from a Bacillus Sp. DT7. World Journal of Microbiology and Biotechnology, 16 (3), 277-82. https://doi.org/10.1023/A:1008902107929.

Guven, K., Bekler, F., \& Gul, R. (2018). Thermophilic and Halophilic Microorganisms Isolated from Extreme Environments of Turkey, with Potential Biotechnological Applications. In Extremophiles in Eurasian Ecosystems: Ecology, Diversity, and Applications, Microorganisms for Sustainability, Springer N. https://doi.org/10.1007/978-981-13-0329-6.

Kubra, K., Ali, S., Walait, M., \& Sundus, H. (2018). Potential Applications of Pectinases in Food, Agricultural and Environmental Sectors. Journal of Pharmaceutical, Chemical and Biological Sciences, 6(2), 23-34.

Li, Q., Ray, C., Callow, N., Loman, A., Islam, S., \& Lu-Kwang, J. (2020). Aspergillus niger production of pectinase and $\alpha$-galactosidase for enzymatic soy processing. Enzyme and microbial technology. 134, 109476.

Naquiche, A. (2014). Aislamiento e identificación de bacterias termófilas productoras de proteasas provenientes de los géiseres de Calientes, Candarave, Tacna-Perú (tesis de pregrado). Universidad Nacional Jorge Basadre Grohmann, Tacna. Perú.

Roy, K., Sujan, D., Kamal, U., Barua, R., \& Hossain, T. (2018). Extracellular Pectinase from a Novel Bacterium Chryseobacterium indologenes Strain SD and Its Application in Fruit Juice Clarification. Enzyme Research (March): 1-7.https://doi.org/10.1155/2018/3859752.

Salem, S. (2018). Production of Pectinases from Thermophilic Anoxybacillus Species Isolated from El-Wahat desert soil, Egypt. Egypt. J. Biotechnol, 47 (July).

Tamura, K., Dudley, K., Nei, M., \& Kumar, S. (2007). MEGA4: Molecular Evolutionary Genetics Analysis (MEGA) Software Version 4.0. Molecular Biology and Evolution, 24 (8): 1596-99. https://doi.org/10.1093/molbev/msm092.

Yildirim, V., Ozkan, M. Ozgencli, I., Sisecioglu, M., Adiguzel, A., \& Adiguzel, G. (2017). Purification and Biochemical Characterization of a Novel Thermostable Serine Alkaline Protease from Aeribacillus pallidus C10: A Potential Additive for Detergents. Journal of Enzyme Inhibition and Medicinal Chemistry, 32(1), 468-77.https://doi.org/10.1080/14756366.2016.1261131.

Zapata, H., \& Castellanos, R. (2014). Aislamiento e identificación de bacterias celulolíticas termófilos de géiseres naturales de Candarave-Tacna. Ciencia \& Desarrollo (18), 29-36. 